\title{
Uso de fuentes de información audiovisual en los medios digitales españoles: repositorios 2.0 de vídeos.
}

\author{
Matilde Roa Amaya \\ Jorge Caldera Serano
}

Recibido: 15.06.2012

Aceptado: 20.07.2012

\section{Resumen}

Se analiza la utilización de material audiovisual por parte de medios digitales con presencia en formato papel, para demostrar así que existe una clara hibridación de medios y formatos en los medios digitales actuales. Para ello se ha analizado el periódico El País y El Mundo, para plasmar la existencia de la utilización de material puramente audiovisual para completar o facilitar información a sus lectores textuales y visuales. Además se lleva a cabo la sistematización de la procedencia de las imágenes, determinando así el uso de fuentes propias y/o externas.

\section{Palabras clave}

Información Audiovisual, Periódicos digitales, Recurso audiovisual, Utilización

\section{Abstract}

We analyse the use of audiovisual material from digital media presence in paper format, in order to demonstrate that a clear hybridization of media and formats in today's digital media. This has been discussed the newspaper El País and El Mundo, to capture the existence of the use of purely audiovisual material to complete or provide information to their readers textual and visual. It also holds the systematization of the origin of the images, thus determining the use of its own sources and / or external

\section{Keywords}

Audovisual information, Newspapers, digital audio-visual resource, use 


\section{INTRODUCCIÓN}

La evolución trepidante de la tecnología de la información y de la comunicación en las últimas décadas del Siglo XX han generado un cambio importante en el paradigma informacional y también en el comunicacional. Se han abierto nuevos métodos de transmisión, se han implantado nuevas culturas comunicativas, se han detectado nuevos nichos de mercado derivado de la clara implantación e integración en la vida cotidiana de la tecnología.

Está aceptado el concepto de "nativos digitales" para determinar a aquella generación o generaciones (los que ahora tienen menos de 25 años) que han nacido rodeado de pantallas, con capacidad multisecuencial de realización de acciones, con conocimientos adquiridos por el hábito que a los inmigrantes digitales nos sigue costando un gran esfuerzo, y que muchos de ellos son inalcanzables para generaciones anteriores: los excluidos digitales.

La red de comunicación Internet es la herramienta fundamental que está determinando muchos de los cambios. La globalización potencial del acceso a la información, la facilidad de uso, el ambiente audiovisual y multimedia que lo hace especialmente atractivo, han desembocado en una nueva sociedad que hemos denominado Sociedad de la Información. Aunque dicho paradigma es anterior a la aparición de Internet sí que se ha potenciado con la expansión de la Red.

Y esta nueva realidad global, empresarial, informativa y comunicacional no ha pasado desapercibida a las empresas dedicadas al ámbito de la difusión de información de actualidad. Los medios de comunicación tradicionales, tanto en su versión en papel, radiofónica o televisiva, han buscado y buscan su lugar en este complejo entramado donde existe una multiplicación de oferta y con una cultura cambiante por parte de los nativos digitales de acceso a la información.

Los medios han detectado la necesidad de estar presentes en la Red si quieren seguir estando presente en la Sociedad, si quieren seguir compitiendo con otros medios. De esta lucha surge el Periodismo Digital, de la necesidad de buscar nuevos clientes y dar valor añadido en muchos casos a la información que ofrecían hasta ahora en los medios de comunicación tradicional. La bidireccionalidad comunicativa sólo es posible con el uso de las tecnologías de la comunicación y este nuevo aspecto se está explotando con las creación de la web 2.0 y muy especialmente con el uso de las redes sociales.

\section{JUSTIFICACIÓN}

Podríamos asegurar que prácticamente todos los medios de comunicación cuentan con su "álter ego" en la Red, en la cual no sólo vuelcan sus contenidos textuales -en caso de los medios en papel- sino que facilitan una gran cantidad de información distinta a la tradicional.

Los medios ya no son tan tradicionales en la red, todos son medios híbridos, incluyendo información en diferentes formatos y de diferente naturaleza. El material audiovisual es muy utilizado como reclamo pero cada vez más es utilizado también como método informativo en la prensa digital. 
Esta hibridación hace necesario abordar estudios que clarifiquen en qué medida son utilizados los recursos audiovisuales en los medios tradicionales, con el fin de valorar aspectos tales como la accesibilidad, el uso, el abuso de esta información, la validez informativa, etc. y aspectos como el análisis de la información desde el punto de vista de las fuentes de información utilizadas, lo cual nos marcará la tendencia en los medios impresos tradicionales a convertirse en medios multimedia.

Estos recursos audiovisuales se localizan en repositorios organizados con la misma estructura de las noticias del medio. Se denominan además 2.0 ya que son elementos que cuentan con una bidereccionalidad comunicativa entre los medios y los lectores/clientes. Aunque el medio selecciona y difunde de forma unilateral estos vídeos, sí que existen en los medios la capacidad de que los lectores puedan facilitar recursos audiovisuales, y sobre todo, facilitan la posibilidad de analizar y comentar estos vídeos.

\section{OBJETIVOS DEL TRABAJO}

El presente trabajo cuenta con una serie de objetivos que va a ser abordados partiendo de una serie de hipótesis de partida, los cuales serán validados o rebatidos a tener del trabajo de campo realizado.

Objetivo 1: Determinación de la utilización de material audiovisual por parte de los medios digitales de tradición textual.

Aunque todos somos conscientes al ser usuarios de estos recursos web de la utilización de material audiovisual era necesario corroborar en un primer momento que se utilizan de forma sistemática estos recursos audiovisuales en estos medios.

\section{Objetivo 2: Determinación del uso de fuentes internas y externas en la prensa digital.}

Una vez se logre demostrar el uso de información audiovisual de procedencia interna y externa a la institución que publica el periódico digital, habrá que demostrar la presencia de material de fuentes propias como externas, tomando también como externa aquellas que, aunque procediendo del mismo grupo empresarial, no está incluido en el organigrama del periódico.

\section{Objetivo 3: Determinación la procedencia de las fuentes externas utilizadas por los medios} digitales analizados.

Saber cuáles son las empresas que distribuyen información a los medios no solo nos facilita conocer las empresas externas más importantes, sino que también nos podría ayudar a determinar la tendencia ideológica de los medios digitales. No obstante, existe una clara globalización en el uso de las fuentes externas siendo posteriormente en las redacciones donde se facilita y otorga un valor moral, ético e ideológico. 


\section{METOdOLOGÍA}

La metodología del trabajo cuenta con una revisión bibliográfica y un trabajo de campo que se han realizado de forma secuencial, las cuales hemos estructura por medio de fases:

\section{Fase 1. Revisión bibliográfica y análisis de fuentes.}

Se ha interrogado las bases de datos más relevantes para la búsqueda de esta información, como DIALNET, ISI, SCOPUS y consulta directa en catálogos y bibliotecas de nuestro entorno. Existe nula producción sobre dicho la determinación de dicho factor.

\section{Fase 2. Selección de la muestra.}

La muestra seleccionada para realizar la posterior fase de análisis de campo ha sido:

- Periódicos nacionales

$$
\begin{array}{ll}
\text { - El País } \\
\text { - El Mundo }
\end{array}
$$

La motivación de la elección de estos medios ha sido que tanto el País como El Mundo son los medios que cuenta con mayor venta en su versión en papel y mayor visibilidad en periódicos de tirada nacional (excluidos deportivos).

Este trabajo no cuenta con valor estadístico. Los datos, por tanto, no son extrapolables a otra población. No obstante, se estima que la imagen fija que ofrecen los datos nos puede aportar una tendencia en la inclusión y uso de material audiovisual en los medios digitales.

\section{Fase 3. Trabajo de campo.}

Durante una semana se han analizado los tres medios en horario de tarde prefijado:

16:00 h. El País.

18: 00 h. El Mundo.

Determinar el horario es importante para así determinar las nuevas noticias en un periodo de 24 horas, ya que las noticias sólo se han contabilizado una sola vez: la primera vez que aparecen.

La fecha en la cual se ha llevado a cabo el estudio ha sido de 14 de junio a 20 de junio de 2011.

Para el análisis de estas noticias se ha confeccionado una ficha en la cual se incluye una serie de información:

- Fecha en la que aparece por primera vez la noticia audiovisual:

- Existen noticias que están presentes en la red durante varios días por motivos normalmente periodísticos. En el estudio sólo se han contabilizado en la fecha de primera aparición. Para ello la ficha de análisis cuenta con una serie de información sólo de utilidad interna para la no repetición de la noticia, como ha sido la indicación de un título y la confección una frase explicativa de su contenido, de tal forma que se pudiera detectar rápidamente si dicha noticia es repetida del día anterior o se ha utilizado con anterioridad. 
- Sección a la que pertenece la información.

- Para ello se ha realizado una distribución clásica en los medios, señalando las secciones/temas de nacional, internacional, política, cultura, sociedad, deportes y blogs.

- Se ha realizado una primera clasificación atendiendo a si dicha fuentes de información audiovisual es propia o externa.

- Se ha tomado como interna cuando es el propio medio digital el que ha captado la información y así lo determina en la fuente. Por el contrario las fuentes externas son aquellas que, incluso siendo del mismo grupo de comunicación, señalan claramente que su procedencia es distinta a la señalada con anterioridad. Para determinar la fuente es necesario contar con elementos tales como: la rotulación de la información, "la mosca" que aparece en la noticia, logotipos rotulados o presentes en micrófonos de los periodistas, determinación de ubicación de un periodista a un medio concreto, así como referencias culturas y personales que facilitan dicha identificación.

- Determinación de la fuente concreta en el caso de fuentes externas.

- Una vez se ha determina la fuente de información externa se ha intentado analizar cuáles son exactamente las fuentes de procedencia de las mismas.

\section{Fase 4. Análisis de datos.}

Una vez recopilado los datos, se realiza el análisis y valoración de los mismos, validando así las hipótesis planteadas.

\section{VALIDACIÓN DE HIPÓTESIS Y CONCLUSIONES.}

\section{Hipótesis 1: Los medios digitales de tradición textual utilizan material audiovisual como elemento informativo.}

\section{VALIDADA/ REFUTADA}

Análisis:

Esta primera hipótesis resulta ser validada tras realizar el análisis de las noticias de los tres medios en una semana de duración. Los dos periódicos nacionales cuentan con material audiovisual utilizado como elemento informativo. Cada uno de estos periódicos digitales contiene su información en forma de texto y algunas de estas informaciones las complementa un archivo en formato vídeo.

El total de información audiovisual que incluye el periódico el País en la semana analizada asciende a un total de 53 noticias audiovisuales.

La distribución por días de la semana sería la siguiente: 


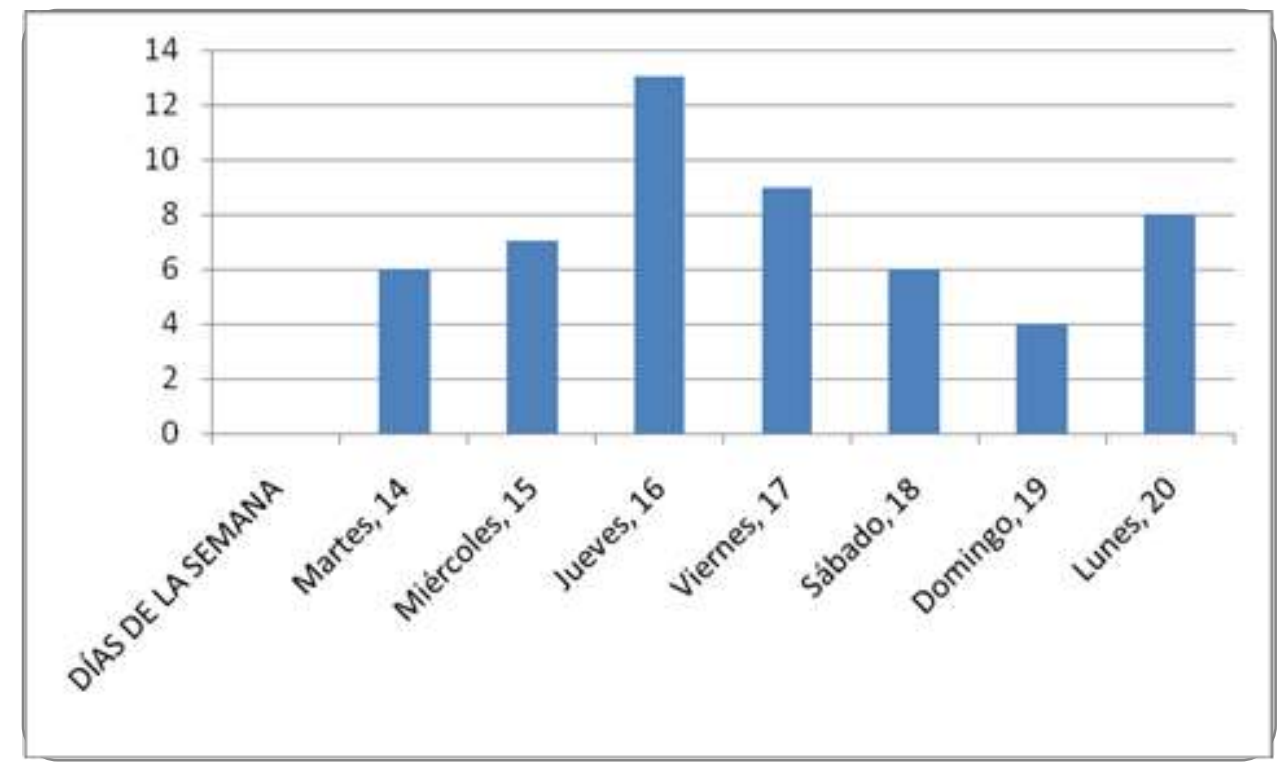

Figura 1. Distribución de noticias AV de El País

El número total de noticias que ofrece el Diario El Mundo en su versión digital alcanza un total de 146 durante la semana analizada.

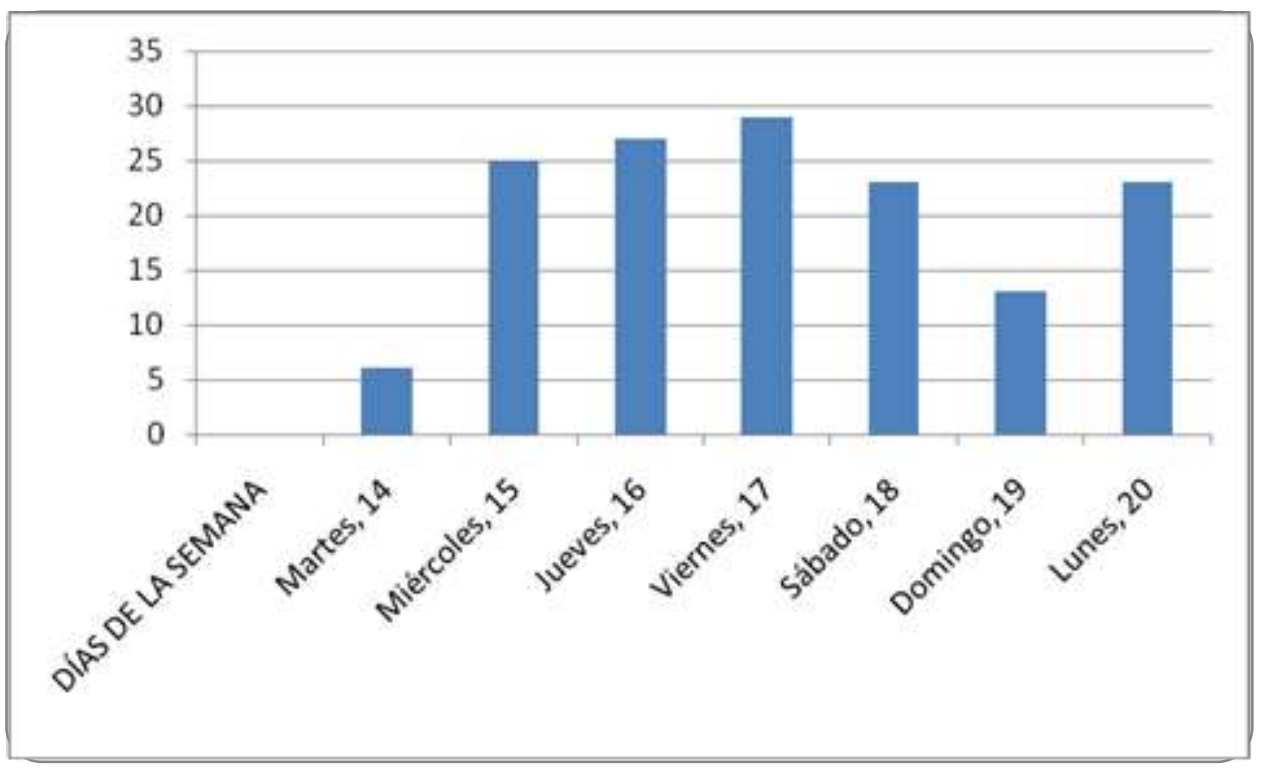

Figura 2. Distribución de noticias AV de El Mundo 
Hipótesis 2: Los medios cuentan con información propia y adquirida a empresas externas entre su material audiovisual.

VALIDADA/ REFUTADA

Análisis:

Los resultados indican que todos los medios digitales analizados cuentan con información audiovisual tanto elaborada por el propio medio como elaborada por fuentes de origen externo.

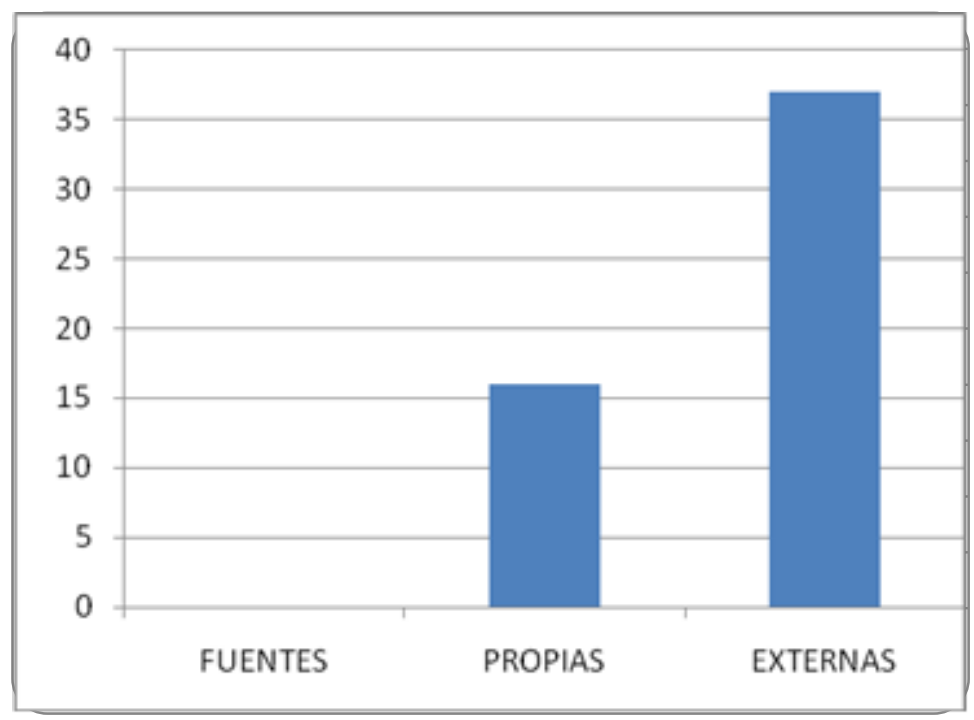

Figura 3. Distribución de noticias AV El País: fuentes propias/externas

Apartado realmente interesante es el de la proveniencia de las fuentes de sus vídeos. Las fuentes externas duplican a las elaboradas por el propio medio (37 noticias de procedencia externa y 16 interna). 


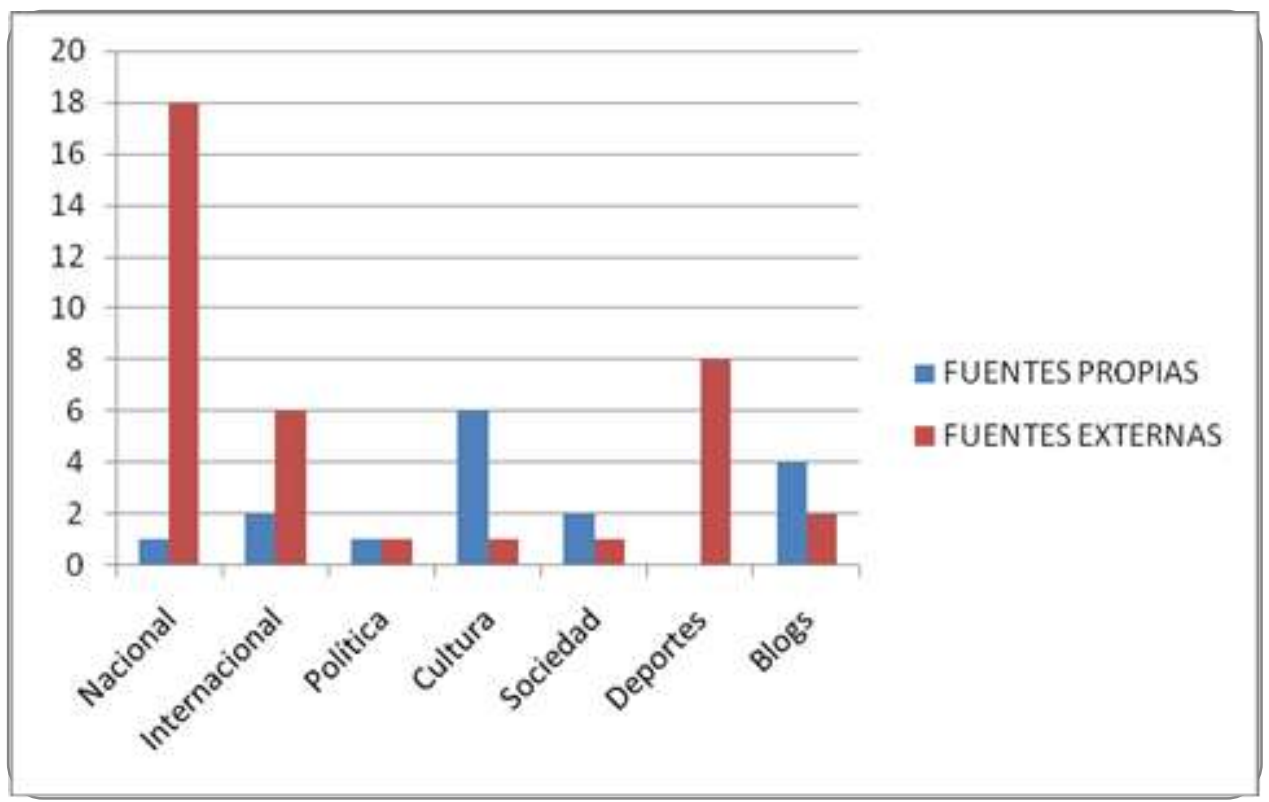

Figura 4. Distribución de noticias AV El País Propias/Externas por secciones

El gráfico demuestra que, a grandes rasgos, las fuentes propias elaboran noticias con contenido cultural, sin embargo, las externas son utilizadas para el ámbito nacional.

Un punto destacado es el tema deportes. Las fuentes propias quedan a manos de las externas la elaboración de noticias sobre este tema.

La sección blogs contiene noticias elaboradas por el propio medio, sobre todo, por el contenido que ofrece sobre Iñaki Gabilondo, cuyos vídeos son elaborados por El País.

En el tema política, ambas fuentes se encuentran equilibradas. 


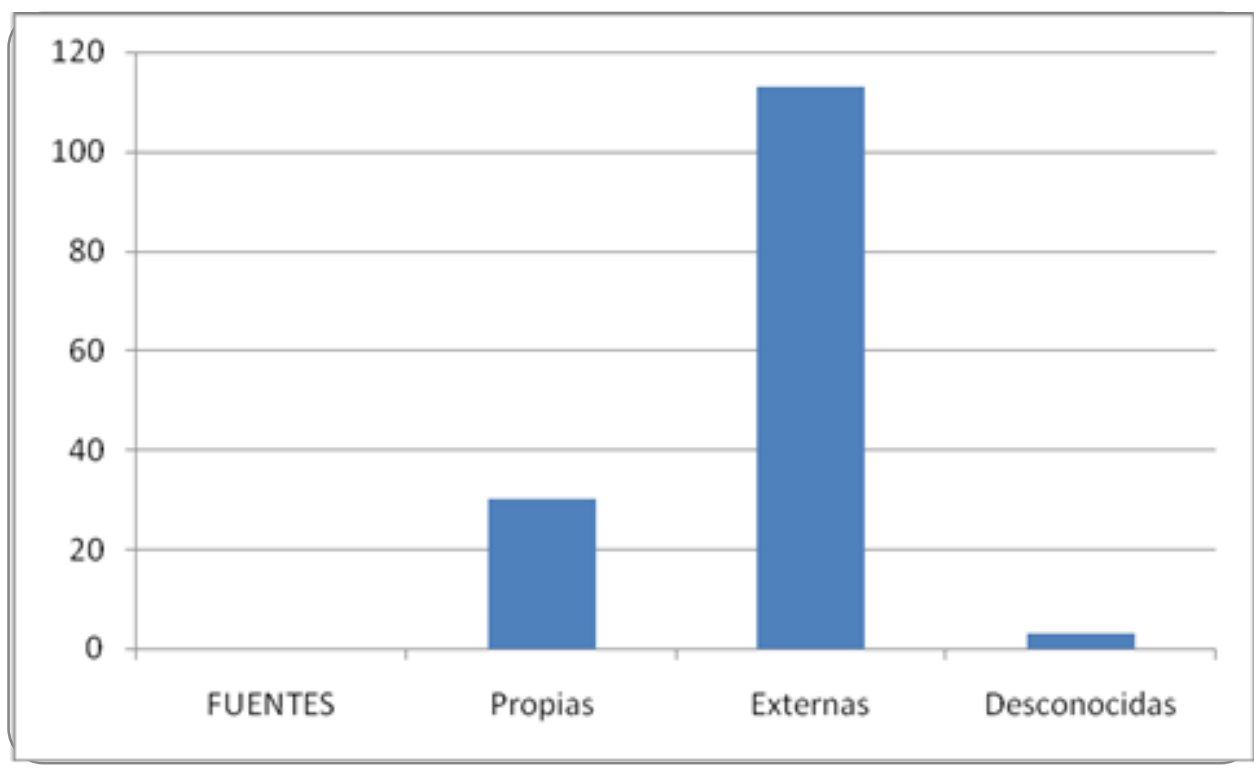

Figura 5. Distribución de noticias AV El Mundo: fuentes propias/externas

Elmundo.es ofrece un amplio número de noticias que provienen de fuentes externas, tales como agencias de noticias, que de vídeos elaborados por el propio medio. Asimismo, encontramos un total de 3 noticias audiovisuales cuyas fuentes son desconocidas y no se indica de dónde proceden y quién las ha elaborado.

No obstante, el número total de noticias audiovisual realizadas por un medio impreso es significativo, ya que 30 noticias del total representan un número significativo.

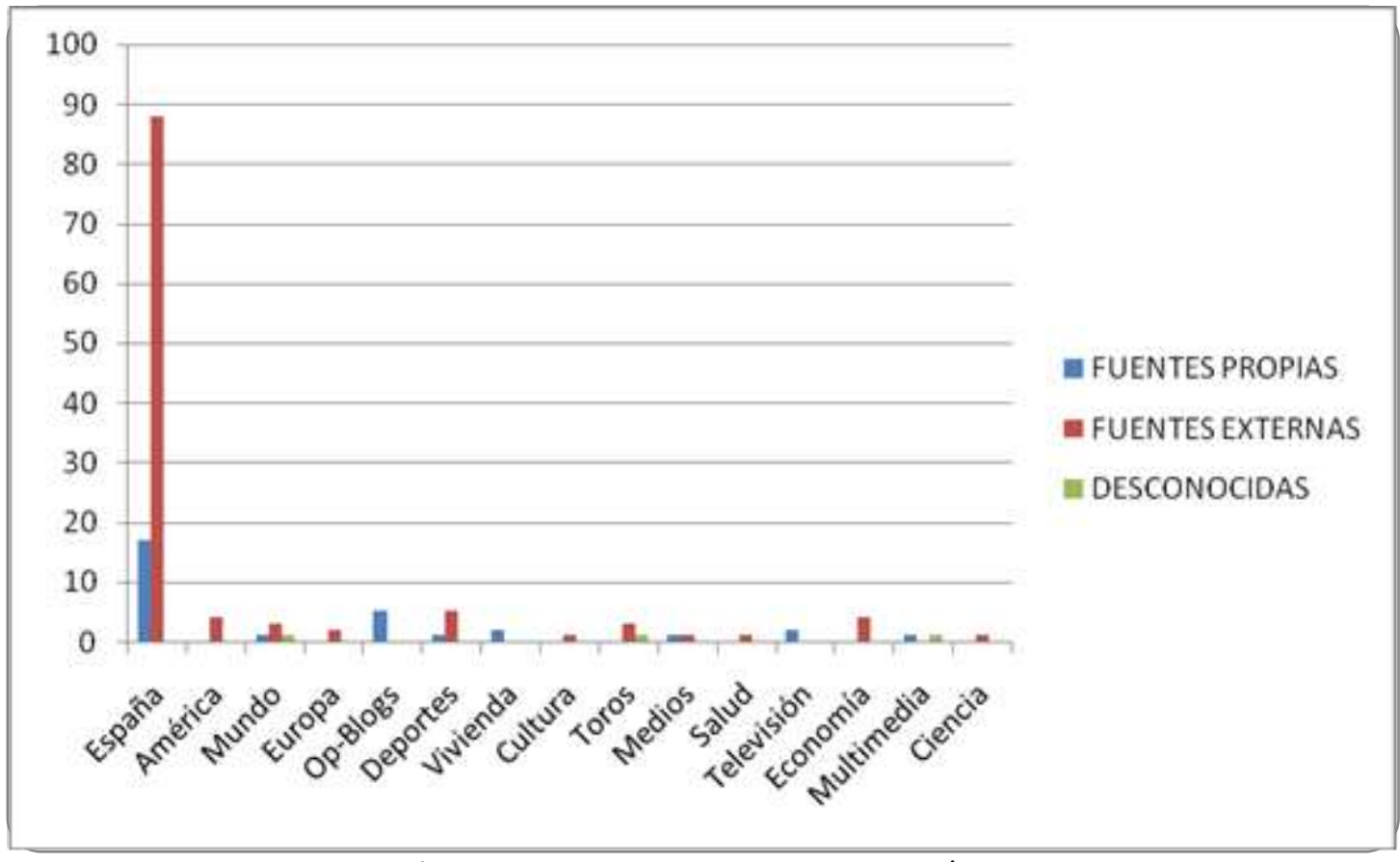

Figura 6. Distribución de noticias AV El Mundo Propias/Externas por secciones 
El gráfico demuestra que la mayoría de las fuentes de las secciones en las que se divide este diario no son elaboradas por el propio medio. Se observa una notable diferencia en el caso de las noticias que pertenecen a la sección "España".

Los vídeos que pertenecen a las secciones como "América", "Europa" y "Economía" provienen, exclusivamente, de agentes externos al propio medio.

Sin embargo, cuando nos referimos a las secciones "Op-Blogs" y "Televisión", los vídeos que contienen estas secciones son elaborados por el medio en cuestión.

Hipótesis 3: La presencia de las fuentes externas supera a las fuentes internas. VALIDADA/ REFUTADA

Análisis:

Se confirma esta tercera hipótesis, además, en cada uno de los periódicos analizados. Todos ellos contienen un gran número de información audiovisual proveniente de agentes externos $y$, en menor proporción, cuentan con información elaborada por ellos mismos. Al ser periódicos que tienen su origen en el soporte papel, están adaptándose aún al gran medio de comunicación como es Internet, en el que, ante todo, predomina la imagen y el sonido sobre el texto. Además, un periódico no tiene gran alcance informativo directo, con lo que tiene que estar suscrito a un generador de noticias (como son las agencias de noticias) que le suministren la información desde cualquier punto geográfico.

Hipótesis 4: La información internacional cuenta con más fuentes audiovisuales externas en los medios

VALIDADA/ REFUTADA

Análisis:

Los medios nacionales que se han analizado en el presente trabajo de investigación contienen una mayor proporción de material audiovisual internacional procedente de ámbito externo que propio, con lo que, tras el análisis de la información audiovisual de los periódicos de tirada nacional, El País y El Mundo, esta hipótesis resulta validada. Acceder a material audiovisual de ámbito internacional es muy complicado para un diario considerado y detenido, en mayor medida, en la información de carácter nacional; esto hace necesaria la contratación de agencias de noticias externas que proporcionen ese material necesario para completar la información que genere un diario. 
Hipótesis 5: Las agencias de información son las fuentes externas más utilizadas por los medios digitales.

\section{VALIDADA/ REFUTADA}

Análisis:

Tanto los medios nacionales, El País y El Mundo coinciden en la fuente a la que, con mayor frecuencia, recurren: Atlas. Atlas es la agencia de noticias que mayor número de noticias audiovisuales proporciona a los medios estudiados. Le siguen Europa Press y EFE. Esto quiere decir que la información de carácter externa que contienen estos periódicos digitales proviene, en mayor medida, de agencias de noticias, $y$, aunque Youtube sea un portal muy rápido al que acudir, las agencias de noticias lo superan.

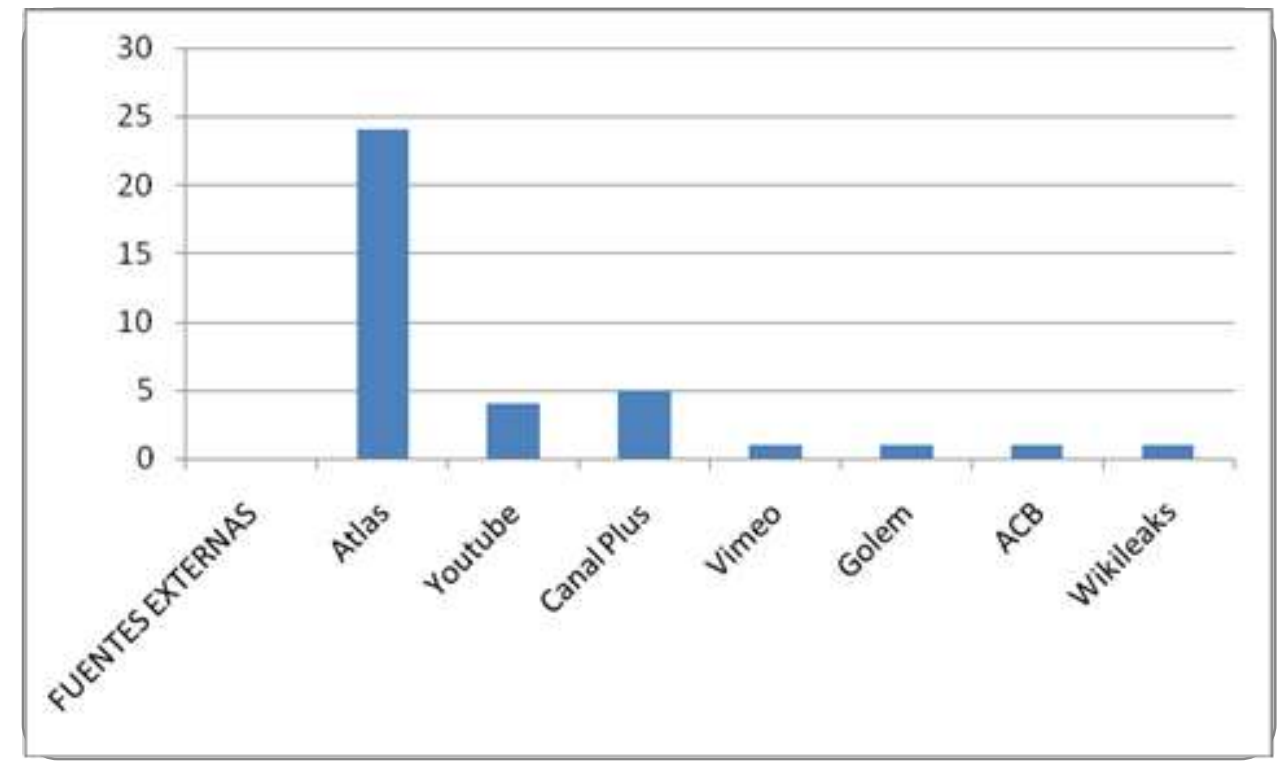

Figura 6. Procedencia de las Fuentes Externas AV de El País

El gráfico demuestra que la agencia de noticias Atlas es la que mayor número de noticias audiovisuales proporciona al medio analizado.

Una segunda fuente es Canal Plus, cadena perteneciente al grupo de comunicación Prisa, al igual que el diario que estamos analizando.

El resto de fuentes intervienen en este diario de una manera puntual. 


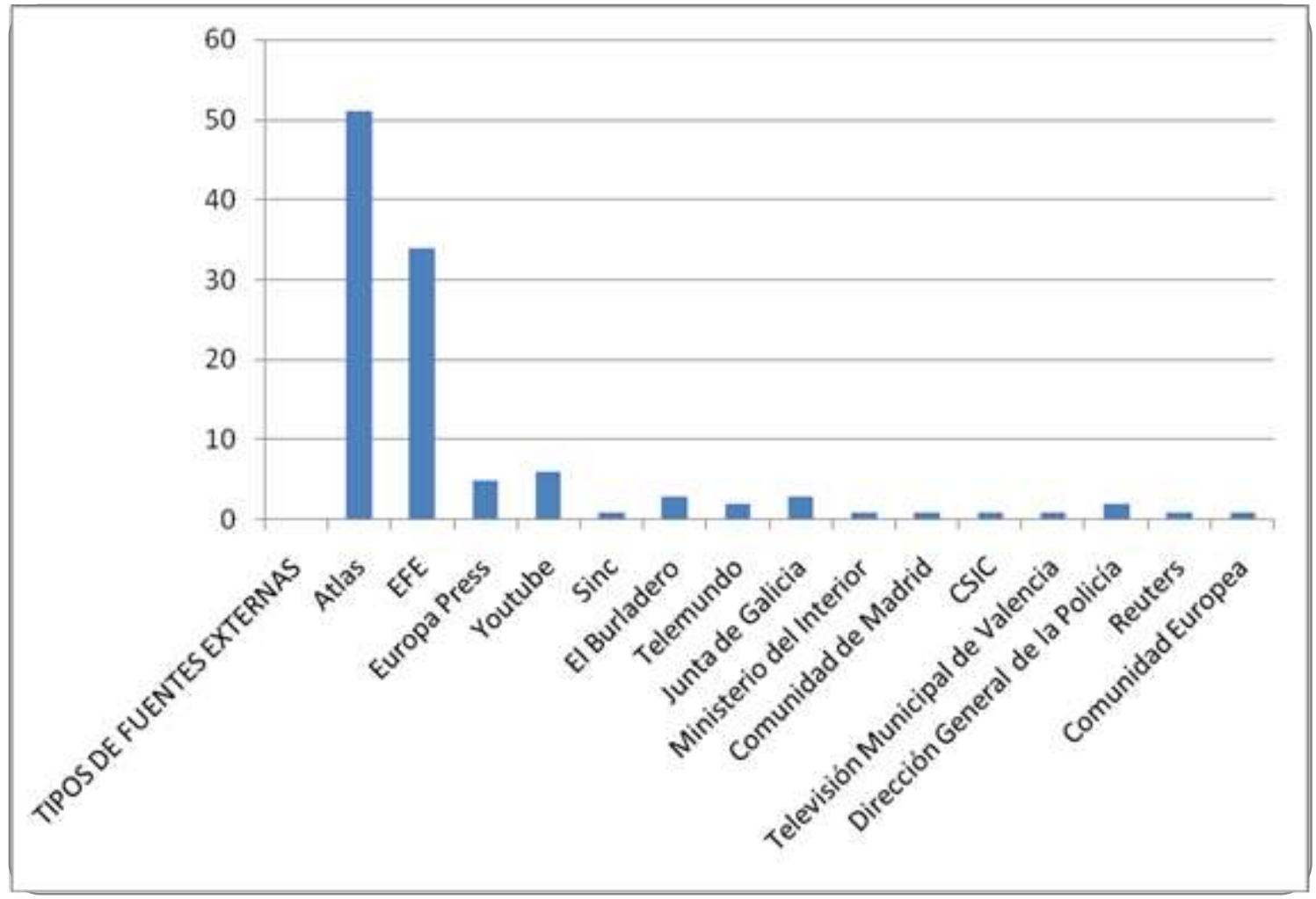

Figura 11. Procedencia de las Fuentes Externas AV de El Mundo

La gran mayoría de los vídeos del diario El Mundo que provienen de fuentes externas pertenecen a agencias de noticias. En concreto son dos las que utiliza con más frecuencia: Atlas y EFE. El resto de fuentes se mantiene de manera estable, optando por diferentes alternativas, entre ellas, Youtube o Europa Press.

\section{RECONOCIMIENTOS}

Este trabajo ha sido financiado por la Junta de Extremadura (Consejería de Educación, Ciencia y Tecnología) y el Fondo Social Europeo dentro del plan de apoyo a las actuaciones de los Grupos de Investigación inscritos en el catálogo de la Junta de Extremadura. GR10019.

\section{WEBGRAFÍA}

\section{http://www.elmundo.es}

Diario El Mundo (Consultado: 1-09-2011)

\section{http://www.elpais.com}

Diario El País (Consultado: 1-09-2011)

\section{http://www.aimc.es//-Datos-EGM-Resumen-General-.html}

Estudio General de Medios (Consultado: 1-09-2011)

\section{http://www.ojd.es/}

Oficina de Justificación de la Difusión (Consultado: 1-09-2011) 